\title{
Mobility and transport of cesium and strontium in soil erosion by water
}

\author{
D. Claval, J. Réal and R. Rouxel \\ Institute of Protection and Nuclear Safety, IPSN/DPRE/SERLAB, \\ Laboratory of Experimental Radioecology, bátiment 180, CE Cadarache, \\ BP. 1, 13108 Saint-Paul-lez-Durance cedex, France
}

\begin{abstract}
It was apparent that the cesium migrates horizontally in greater proportions than the strontium that pooly fixes on the particles and infiltrates into the first centimeter of the soil. One parameter to take into account would appear to be the initial humidity of the soil. The sedimentary crust favours the exportation of cesium and strontium by preventing its infiltration, while at the same time trapping part of the contamination on its immobile particles. In the case of wet discharge, the contamination of cesium tends to disperse. It is now necessary to extend the domain of study of our factors for completing results. Dry periods in structural history and organic contents appeared to be most important.
\end{abstract}

\section{INTRODUCTION}

Water erosion is responsible for the spread of radioactive contaminant through the agricultural catchment area, its redistribution, possible concentration and export towards the aquatic environment, and also for the post-accident contamination of plants through splash of water (figure l).

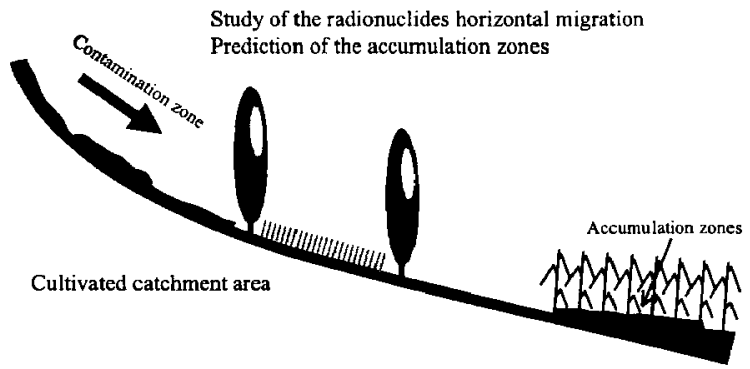

Figure 1: Context of the study. After a nuclear accident the radionuclides deposited in contamination zone will be subject to migration on account to erosion processes. It is necessary to evaluate quantity and localisation of future accumulation zones.

The multiple criterions of the erosion problem in a catchment area are very difficult to integrate as a whole in a model. To solve this difficulty, the catchment area is first decoposed into homogeneous compartments with the same pedologic, agronomic and climatic conditions, in order address the process occurring in each of them.

For studing erosion processes in each homogeneous compartment of the catchment, we have chosen to use an experimental approach. It seemed the necessity to reduce the number of factors, we selected with only two radionuclides, chosen for the environmental and radiological importance, cesium and strontium. In case of a nuclear accident, radionuclides can reach the soil surface by dry-deposition or rain driven 
wet-deposition which can lead to quite distinct behaviours due to the different speciation of these two radionuclides [1-2-3-4].

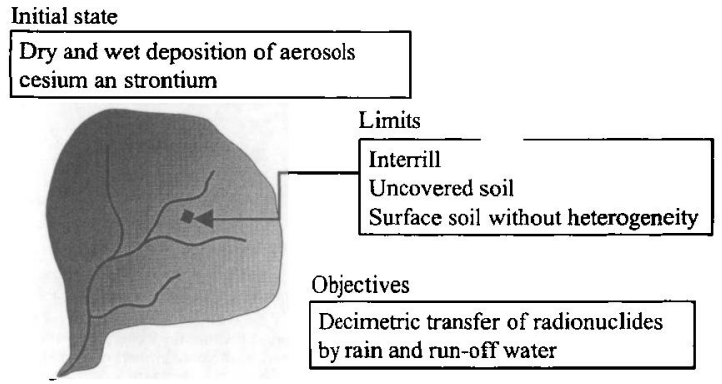

Figure 2: Experimental approach and objective, simplified problems for studied erosion processes in laboratory.

This research has been limited to the interrill of the catchment, because soil particles are mobilized by rain or runoff in the interrill [5]. It is also in the interrills that contaminants are mobilized before being concentrated in the rill. We therefore worked at interrill decimetric scale.

The vegetation reduces soil mobilization and soil transport. Such effects however cannot be studied in the laboratory. It must be mentioned that our sudy using uncovered soil corresponds to the most critical situation for horizontal transport.

The decimetric scale selection prevented the integration of surface heterogeneity, which further complicate erosion process [6].

Our objective was to understand and quantify decimetric transfer without any vegetation, surface or topographic heterogeneities. We used power of rain and run-off for transfer contaminants sorbed on soil particles.

\section{MATERIALS AND METHODS}

Half square meter boxes have been filled with a with silty loamy soil. Contamination has been simulated with the SARA facility (SARA : Simulation of deposit of radioActive aeRosols on Agricultural land). This installation allows for an experimental deposit of dry aerosols. Wet deposits are performed through manual watering with dissolved contaminants. After contamination the experimental boxes are submited to water erosion under an oscillating nozzle sprinkler [8]. Rain gauge $\left(1 / 2 \mathrm{~m}^{2}\right)$ evaluated rainfall at an intensity of $40 \mathrm{~mm} \cdot \mathrm{h}^{-1}$ on $1 \mathrm{~m}^{2}$. Our rain simulations consisted of twelve episodes of 10 minutes, every 24 hours.

Four variables have been studied, the type of deposit, the slope, the soil structural state and bumidity before contamination (Figure 3).

Contaminations have been performed on dry and freshly compacted soils. For studding the influence of the structural and hydric status on the contaminants mobility, we focused on soil moistened by $6.7 \mathrm{~mm}$ of water and soils encrusted after $40 \mathrm{~mm}$ of precipitation on a $10 \%$ slope.

The radionuclides used are both gamma emitters which allow for rapid measurements. In order to quantify the surface displacement of the contamination, we used a small NaI field probe (Aries TC155A) that enables to obtain relative non-destructive measurements of the surface with less than $10 \%$ error. In order to quantify the radionuclides exportation by the run-off water, we sampled the water and the soil downstream of containers after each rain, and measured their radioactivity using a Gamma-Ge counter 
Contaminations have been performed on dry and freshly compacted soils. For studding the influence of the structural and hydric status on the contaminants mobility, we focused on soil moistened by $6.7 \mathrm{~mm}$ of water and soils encrusted after $40 \mathrm{~mm}$ of precipitation on a $10 \%$ slope.

The radionuclides used are both gamma emitters which allow for rapid measurements. In order to quantify the surface displacement of the contamination, we used a small $\mathrm{NaI}$ field probe (Aries TC155A) that enables to obtain relative non-destructive measurements of the surface with less than $10 \%$ error. In order to quantify the radionuclides exportation by the run-off water, we sampled the water and the soi] downstream of containers after each rain, and measured their radioactivity using a Gamma-Ge counter (Eurisys GeHp - EGPC15, type P junction). Fractions of the soil covered with sedimentary crust were estimated by means of a numerical camera (Epson photoPC 600) and the software SigmaScan Pro 4.0. Crust areas were differentiated from residual aggregates from their more brownish colour. It was necessary to perform the threshold selection 12 times per plot to obtain less than $10 \%$ error.

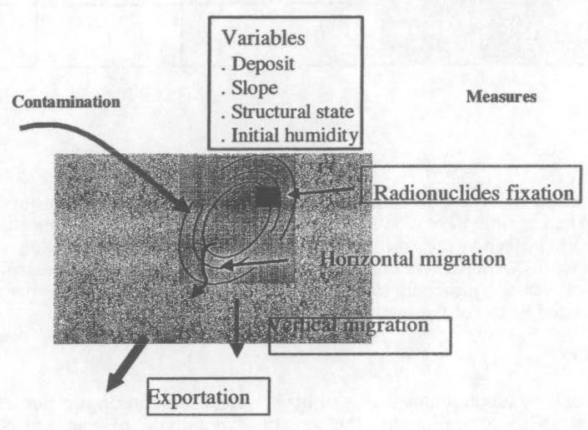

Figure 3: The study limits and the processes experimentally addressed

Finally, we quantified the vertical migration of the radionuclides by sampling soil samples in the surface crusts, at depths of 1 and 2 centimeters. The radioactivity of these samples has been measured by gammaGe. The disaggregating efficiency of each process has been quantified based on batches addressing the radionuclides fixation on soil particles.

\section{RESULTS AND DISCUSSION}

Soil slaking appeared to be the most efficient process promoting radionuclides mobility. Fixation of $134 \mathrm{Cs}$ and $85 \mathrm{Sr}$ was in agreement with the important literature. Radionuclides sorption was very fast on soil particles, a such feature does not seem to have been previously reported. However, it must be strengthened that such results, being limited to the above mentioned experimental conditions, are not get appropriate to support an extrapolation to real and natural soil conditions.

Table 1 recapitulates the role of deposit type, slope, soil structure and humidity on the mobility of radionuclides. Their influence on fixation of ${ }^{134} \mathrm{Cs}$ an ${ }^{85} \mathrm{Sr}$ has not been studied, but previous work allows to propose some hypothesis. Camarasa-Claret [9] showed that Cs and Sr dissolution after dry-deposit can be a long-term process. 
Table 1 : Role of same factors (type of deposit, slope, structural state and humidity of soil) on the mobility of radionuclides $(l$, not studied ; 0 , no effect ; -, decreases mobility ; $t$, increases mobility).

\begin{tabular}{|l|c|c|c|c|}
\cline { 2 - 5 } \multicolumn{1}{c|}{} & Deposit & Slope & $\begin{array}{c}\text { Structural } \\
\text { history }\end{array}$ & $\begin{array}{c}\text { Hydric } \\
\text { history }\end{array}$ \\
\hline Radionuclides fixation & $/$ & $/$ & $/$ & $/$ \\
\hline Horizontal migration & Wet + & $\mathrm{Cs}+$ & $\begin{array}{c}\text { Cs crust - } \\
\text { Sr 0 }\end{array}$ & $\begin{array}{c}\text { Cs wet - } \\
\text { Sr 0 }\end{array}$ \\
\hline Vertical migration & Sr wet + & Sr + & $\begin{array}{c}\text { Cs crust - } \\
\text { Sr crust - }\end{array}$ & $\begin{array}{c}\text { Cs 0 } \\
\text { Sr wet + }\end{array}$ \\
\hline Exportation & 0 & ++ & 0 & 0 \\
\hline
\end{tabular}

The absence of crust and wet-soil increased exportation in contrast to crusted soil which immobilised radionuclides. When sedimentary crusts appeared, fixation was surely enhanced, because clay was upper stratified in crust [11]. When the soil was humidified before deposit, fixation was facilitated by better dissolution of aerosols. After a wet contamination, dispersion of cesium was more important than after dry-deposit, but it was not judicious to study the role of their deposit type because it did not influence exportation of $\mathrm{Cs}$ and $\mathrm{Sr}$ out of the interrill.

\section{CONCLUSION}

The risks of secondary contamination driven by horizontal migration are not negligible. This study has enabled us to establish a outline for the general functioning of our soil samples. Soil slaking is undoubtedly the most efficient disaggregating process prone to mobilising cesium and strontium. It is therefore when the interrill area is immersed that sorption of the radionuclides is reaching its maximun. In addition, the exportation rate is increased on a soil that is not encrusted and wet whereas contaminants tend to persist when a sedimentary crust is formed. There is dispersion of cesium during wet deposition. The surface mobile stock is rapidly eliminated under steep slope conditions.

One might summarise the results by stating that in one winter month ( $80 \mathrm{~mm}$ of precipitation), there would be $40 \%$ of surface spreading of contamination, $60 \%$ of exportation and that only the strontium migrates vertically (Figure 4 ).

Transfer of radionuclides during 1 winter month ( $80 \mathrm{~mm}$ of rain water)

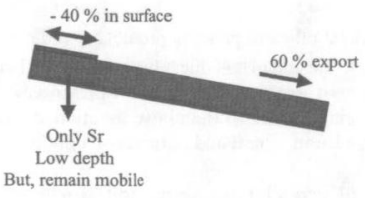

But, mobility overestimate because of parameters choice ( slope, intensity and time rain, nature of the soil)

Figure 4 : Use of results to a soil during 1 winter month with $10 \%$ siope. 
Working on a single soil type has enabled us to establish a scheme of the general functioning, a feature which deserves now a full validation for various types of soil while increasing the complexity of the hydric history.

For an operational expert model to be further elaborated, a prior knowledge of the catchment area is a baseline requirement, but also, designing a reasonably short calculation time appears more important than reaching a high spatial resolution. By applying solid-liquid distribution coefficients to erosion models such as WEPP, the calculated rate of transport in the run-off water may prove satisfactory. In contrast, for the development of a research model, a more mechanistic approach with finer time scales and better resolution of surface obstacles would undoubtelly provide a basis for good anticipation of possible contamination re-concentrations in the catchment area. The LISEM model is a good illustration of this approach.

\section{Acknowledgments}

We are particulary grateful to Y. Le Bissonnais, P. Bonte, M. Jauzein and V. Valles whose discussion and help were greatly appreciated.

\section{References}

[1] Stumm, W., \& Morgan, J. J. Aquatic chemistry. Elsevier Ed (1981).

[2] Nilsson, K., Jensen, B. S., \& Carlsen, L. The migration chemistry of strontium. European Applied Research Report-Nuclear Science Technology. 28 (1) (1985) 149-200.

[3] Cornell, R. M. Adsorption of cesium on minerals : a review. Journal of radioanalyctical and nuclear chemistry, articles. 171 (2) (1993) 483-500.

[4] Claval, D., Real, J., Feurstein, J., \& Rouxel, R. Influence de l'érosion hydrique et du ruissellement sur le transfert en milieu naturel ou agricole des produits de fission émis en cas d'accident nucléaire. Cadarache, (Report L.P.S.N. SERE 97/033P, 1997),

[5] Young, R. A., \& Wiersma, J.L. The role of impact in soil detachment and transport. Water Resource Research. 9 (1973) 1629-1636.

[6] Govers, G., \& Takken, I. "Soil roughness: a management tool for the limitation of runoff and erosion". 16ème congrès mondial de science du sol, Montpellier (1998).

[7] Madoz-Escande, C., Brechignac, F., Colle, C., Dubois, E., Hugon, H., Jouglet, H., Moutier H., Rongier P., Sanchez, A., Shulte EH, \& Zamon, R.. Experimental installation for radioecology research on defined ecosystems subjected to contamination in controlled conditions, Nuclear science and engineering. 139 (1999) 178-191.

[8] Valentin, C. "Problèmes méthodologiques de la simulation de pluie". Érosion agricole des sols en milieu tempéré non méditéranéen. Strasbourg (1978).

[9] Camarasa-Claret, C. Étude de la mise en solution des radionucléides Cs et Sr déposés sur des matériaux urbains. Applications à la décontamination. Thèse Montpellier (1997).

[10] Helming, K., Römkens, M.J.M., \& Prasad, S.N. Surface roughness related processes of runoff and soil loss: a flume study. Soil science society of american journal 62 (1998) 243-250.

[11] Boiffin, J. La dégradation structurale des couches superficielles du sol sous l'action des pluies. ParisGrignon (FR), thèse de l'Institut national agronomique (1984). 